\title{
Econometric Analysis of Development of Real Estate Industry in Zhanjiang
}

\author{
Yanli Xu ${ }^{1,3}$, Dan $\mathrm{Liu}^{2,3,{ }^{*}}$, Bin Chen ${ }^{3}$ \\ ${ }^{1}$ School of Business, Lingnan Normal University, Zhanjiang, Guangdong, 524048, P. R. China \\ ${ }^{2}$ Liabrary, Lingnan Normal University, Zhanjiang, Guangdong, 524048, P. R. China \\ ${ }^{3}$ South China Sea Silk Road Collaborative Innovation Centre, Lingnan Normal University \\ *Corresponding author: liudan100liudan@163.com
}

Keywords: Zhanjiang city; Real estate industry; Econometric analysis

\begin{abstract}
In order to promote the development of real estate in Zhanjiang City, this essay uses the method of econometrics to establish the regression model with the related indicators of real estate development in Zhanjiang from 2000 to 2013 as the econometric analysis. The results show that the total real estate output value of Zhanjiang City is closely related to capital investment and labor input in the real estate industry. Therefore, it can be concluded that in order to promote sustainable development of real estate industry in Zhanjiang, it is necessary to increase capital investment and labor input in the real estate industry.
\end{abstract}

\section{Introduction}

The real estate industry has the characteristics of large industrial value, high correlation and strong industrial driving ability, and healthy and stable development. The real estate industry is of great significance for maintaining and promoting the overall steady economic growth under the current economic background in our country. The urban real estate is not only closely related to people's livelihood, but also closely linked with the trend of economic development. It is one of the important pillar industries in the national economy. From the historical experience of national economic development, we can see that the development of the real estate industry will have a lasting impact on economic development and spread to many industries, including the steel industry, building materials industry, construction industry, transportation industry, service industry, financial industry, chemical industrial, mechanical and electrical industry, communications, commerce, urban landscape, shopping and tourism, work and living environment and standards of social civilization, are closely related with the real estate industry. The real estate industry's impact on the national economy is crucial.

Zhanjiang is in the process of accelerating urbanization. At this stage, the population will quickly concentrate on urban areas and form a large demand for urban real estate. Therefore, it is necessary to analyze the influencing factors of real estate development in Zhanjiang .

\section{Model Setting and Data Description}

Table 1 shows real estate development effectiveness indicator data in Zhanjiang from 2000 to 2013. The data is from Zhanjiang City Statistical Yearbook and Zhanjiang City Government portal. 
Table 1 Table of real estate development effectiveness indicator data in Zhanjiang

\begin{tabular}{|l|r|r|r|}
\hline Year & $\begin{array}{c}\text { Total output of real estate } \\
Y \text { (million yuan) }\end{array}$ & $\begin{array}{c}\text { Capital investment in } \\
\text { real estate industry } \\
K \text { (million yuan) }\end{array}$ & $\begin{array}{c}\text { Labor input of real estate industry } \\
L\end{array}$ \\
\hline 2000 & 2762.24 & 785.05 & 3078 \\
\hline 2001 & 4735.59 & 829.91 & 3120 \\
\hline 2002 & 5312.45 & 1066.91 & 3295 \\
\hline 2003 & 5934.53 & 1145.67 & 3275 \\
\hline 2004 & 8898.71 & 1566.62 & 5670 \\
\hline 2005 & 8889.24 & 2078.06 & 7105 \\
\hline 2006 & 10521.04 & 2394.46 & 6546 \\
\hline 2007 & 12509.93 & 3400.17 & 7863 \\
\hline 2008 & 14807.27 & 3675.42 & 9684 \\
\hline 2009 & 17786.64 & 4727.28 & 10305 \\
\hline 2010 & 21089.69 & 7504.25 & 11853 \\
\hline 2011 & 26384.87 & 10745.97 & 11990 \\
\hline 2012 & 31110.97 & 11496.31 & 12356 \\
\hline 2013 & 33934.04 & 15478.46 & 13395 \\
\hline
\end{tabular}

The real estate investment in real estate capital $K$ and real estate labor input $L$ of Zhanjiang City are the vertical axis, and Zhanjiang City real estate output value $Y$ is abscissa. Make scatter plot, which is as shown in Figure 1.

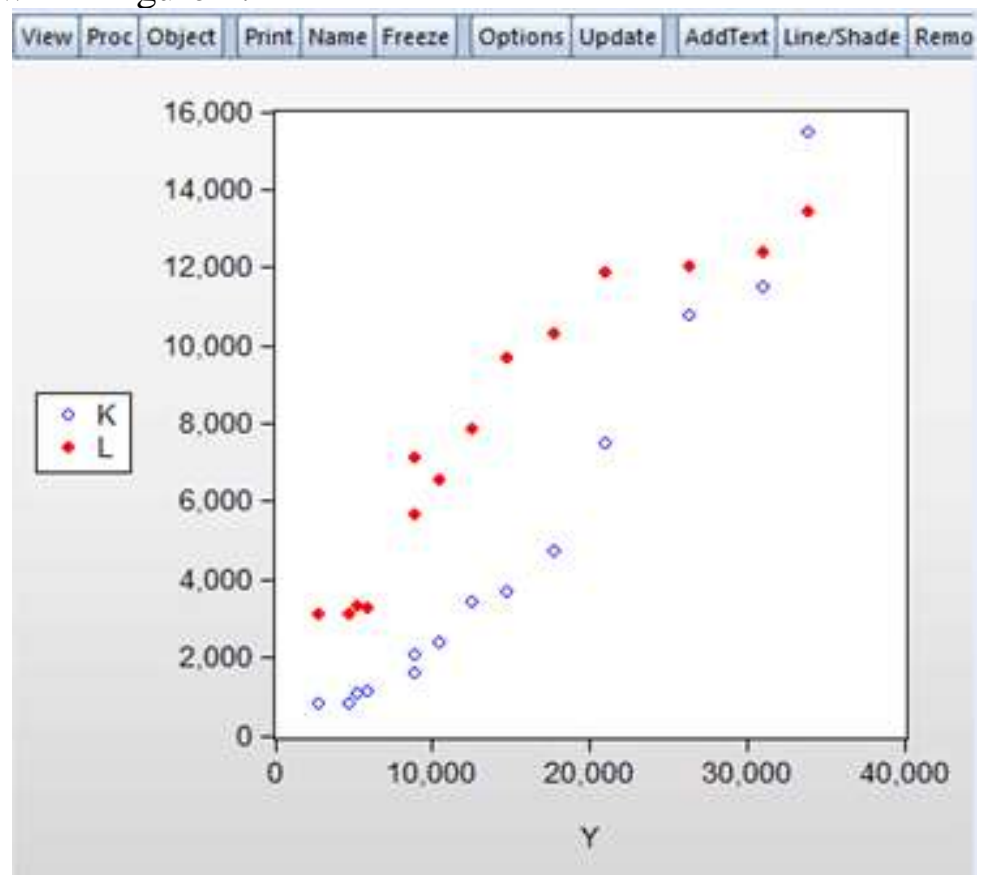

Figure 1 Scatter plot of total value of out-put $Y$, capital investment $K$, and labor investment $L$ of Zhanjiang

As can be seen from the scatter plot, Zhanjiang City real estate total value of output $Y$, capital investment $K$, real estate labor input $L$ have a linear relationship. According to the scatter plot, build a regression model:

$$
Y_{t}=\beta_{0}+\beta_{1} K_{t}+\beta_{2} L_{t}+\mu_{t} \quad t=1,2, \cdots, 14
$$




\section{Estimation of Model Parameters}

Using EVIEWS software and the method of OLS to estimate the parameter of the model, the results are shown in Figure 2

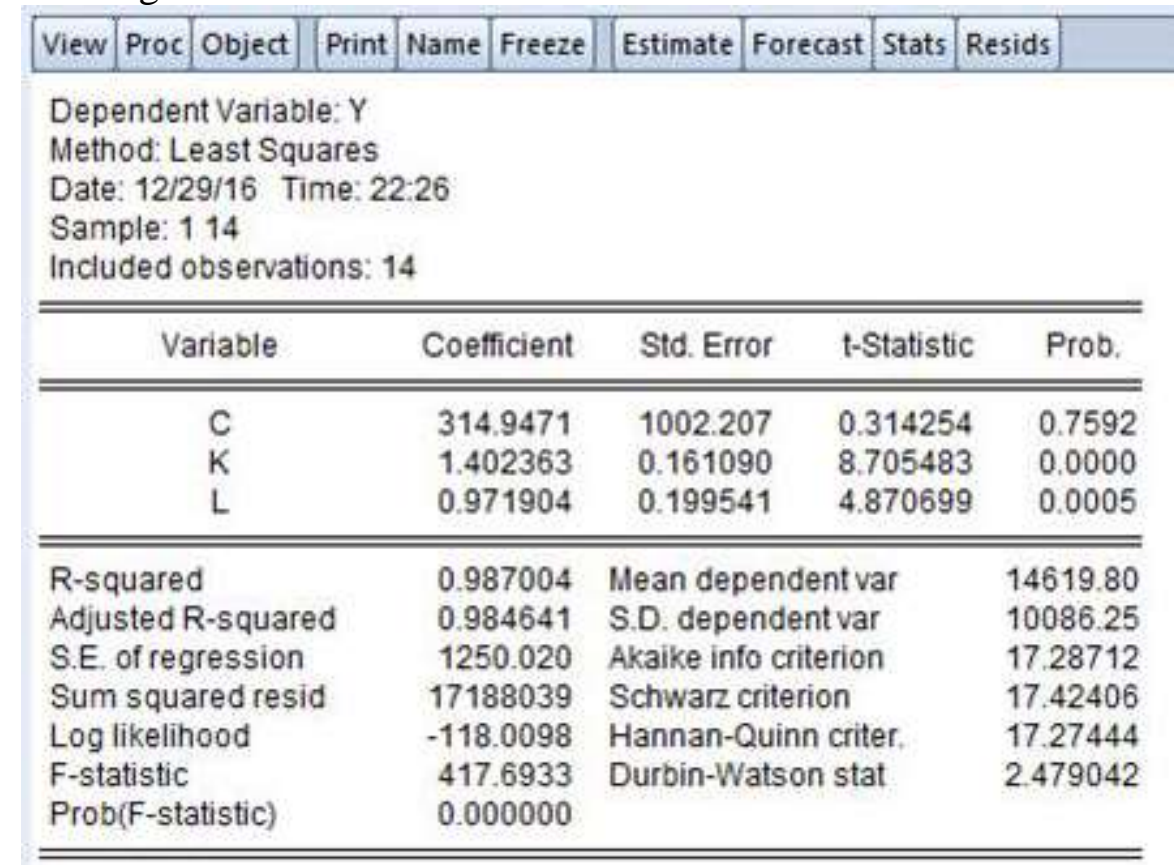

Figure 2 The regression results of real estate industry output and real estate industry capital investment and labor force in Zhanjiang

The regression equation is as follows:

$$
\hat{Y}_{t}=314.9421+1.402363 K_{t}+0.971904 L_{t} \quad t=1,2, \cdots, 14
$$

\section{Conclusion}

When the other conditions remain unchanged, when the capital investment of real estate in Zhanjiang $K$ is increased by 1 , the total value of out-put of real estate industry in Zhanjiang is increased by 1.402 . When the other conditions are unchanged, when the labor input of real estate industry $L$ is increased by 1 , the total output of real estate in Zhanjiang will be increased by 0.972 .

\section{Acknowledgements}

It is a pleasure to acknowledge the support of the project from XU Yan-li being selected in the introduction of shortage top talent of "Sailing up (Yangfan) project" in Guangdong Province in 2014. The project is Leading Industry Development Strategy Research in Emerging Areas in Western Guangdong for Accelerating the Economic Development of Western Guangdong.

It is a pleasure to acknowledge the support from the talents introduction project of universities in Guangdong Province and from Guangdong University of Petrochemical Technology. The project is the Coordinating Development Model Construction and the Path Research of Technical Capability and Technology Management Capability in Equipment Manufacturing Industry.

It is a pleasure to acknowledge the support from the talents introduction project of Guangdong University of Petrochemical Technology. The project is Research on the Coordinating Development Model and Path of Technical Capability and Technology Management in Maoming (513088).

It is a pleasure to acknowledge the support from comprehensive reform experiment of the Major of International Economics and Trade in Guangdong University of Petrochemical Technology.

It is a pleasure to acknowledge the support from International Education Department in 
Guangdong University of Petrochemical Technology. The project is Research on Teaching Quality Evaluation for the Major of International Economics and Trade in English in the Background of International Education (2014GDUPTGJ-07).

It is also a pleasure to acknowledge the support from South China Sea Silk Road Collaborative Innovation Center in Lingnan Normal University (2017EL03).

It is also a pleasure to acknowledge the support from Excellent Course "Macroeconomics" in Teaching Quality and Teaching Reform Project in Lingnan Normal University in 2017 (114961700227).

\section{References}

[1] Liu Zhengshan. Real Estate Investment Analysis[M]. Dongbei University of Finance and Economics Press, 2004

[2] Yang Hong. Influence of Real Estate in Guangzhou on the Economic Growth - Empirical Study Based on Panel Data[J]. Economic Study, 2012

[3] Ruan Yueping. Study on Current Development Situation of Real Estate Market and Countermeasures - Take Ho Chi Minh City as Example[J]. Journal of Beijing Jiaotong University, 2013

[4] Bai Junyu. Study on Implementation Effect of National Real Estate Policies in Zhanjiang City [J]. Journal of Zhanjiang Ocean University, 2013

[5] Liu Yao. Study on Countermeasures of Sustainable Development of China's Real Estate Industry - Take Henan Province as Example[J]. Journal of Henan University, 2013

[6] Wang Zhaofeng, Peng Jizeng. Problems and Countermeasures of Domestic Real Estate Market[J]. Journal of Jiangxi Agricultural University (Social Science Section), 2004

[7] Real Estate Study Center of Shanghai Academy of Social Sciences, Shanghai Housing Agent Economy Society. China's Real Estate Study[J]. Shanghai Academy of Social Sciences Press, 2003

[8] Wang Jiating. Empirical Analysis and Route Dependence of Non-coordinated Development of Urban Planning and Real Estate Development[J]. China's Real Estate Finance, 2005

[9] Li Huanjiao, Zhang Hanxu. Discussion on Sustainable Development Notions of Ecological Environment in Development of Urban Real Estate[J]. Public Sciences, 2005 